\title{
Comparative Epidemiology of Monosporascus Root Rot and Vine Decline in Muskmelon, Watermelon, and Grafted Watermelon Crops
}

\author{
R. Beltrán, A. Vicent, J. García-Jiménez, and J. Armengol, Instituto Agroforestal Mediterráneo, Universidad Poli- \\ técnica de Valencia, Camino de Vera s/n, 46022-Valencia, Spain
}

\begin{abstract}
Beltrán, R., Vicent, A., García-Jiménez, J., and Armengol, J. 2008. Comparative epidemiology of Monosporascus root rot and vine decline in muskmelon, watermelon, and grafted watermelon crops. Plant Dis. 92:158-163.

Disease progression and soil population dynamics of Monosporascus cannonballus ascospores were studied and compared through the entire growing season in muskmelon, watermelon, and watermelon grafted onto Cucurbita rootstock crops. In muskmelon and watermelon, there was a decrease of ascospore counts in soil from transplanting until first symptoms of vine decline were observed. This decrease probably was related to ascospore germination and subsequent root infection. Later, there was a remarkable increase of ascospore counts in a parallel way to the quick development of vine decline symptoms, which lead to plant death. In these crops, root colonization adjusted to first-order linear equations and vine decline progression best correlated with exponential and logistic models. In contrast, there were no symptoms of vine decline on grafted watermelon. Furthermore, the isolation of $M$. cannonballus from Cucurbita roots was considerably lower, perithecia were never observed, and ascospore soil populations remained stable. These results suggest that disease control by grafting onto genus Cucurbita seems to be related primarily by the increased resistance of its root system to infection by $M$. canonballus, and provide further evidence of the use of grafting as a disease management measure for this disease.
\end{abstract}

Additional keywords: Citrullus lanatus, Cucumis melo, Cucurbita rootstocks, soil temperature

Monosporascus root rot and vine decline caused by the soilborne ascomycete Monosporascus cannonballus Pollack \& Uecker affects cucurbit crops worldwide $(7,13)$. Symptoms caused by this pathogen in the root system include necrosis and lack of most of the secondary and tertiary feeder roots. Consequently, the root system is unable to maintain adequate water and mineral uptake to sustain the aboveground parts of the plant. This results in complete wilting and death of affected plants prior to fruit maturity that, usually, lead to a total loss of the crop $(13,14)$. Muskmelon $(\mathrm{Cu}$ cumis melo L.) and watermelon (Citrullus lanatus (Thunb.) Matsum \& Nakai) are the main cucurbit species affected by $M$. cannonballus (13). This pathogen also has been reported on other cucurbits such as bottle gourd (Lagenaria siceraria (Molina) Standl.) (27) and cucumber (Cucumis sativus L.) $(11,12)$. Some species of the genus Cucurbita are considered to be tolerant to the disease (15). Currently, in Spain, Monosporascus root rot and vine decline is a severe, damaging disease of muskmelon

Corresponding author: J. Armengol

E-mail: jarmengo@eaf.upv.es)

Accepted for publication 4 August 2007.

doi:10.1094/PDIS-92-1-0158

(C) 2008 The American Phytopathological Society and watermelon in most of the open-field cucurbit-growing areas $(3,10)$.

M. cannonballus survives in soil primarily as spherical and thick-walled ascospores, which germinate under the stimuli of root exudates and soil microflora (23). The fungus colonizes the host roots and, at the end of the cropping season, produces perithecia which can be observed as black and spherical points immersed in the root cortex. These fruiting bodies contain numerous ascospores which are discharged into soil after crop termination $(7,14,23$, 24,29).

M. cannonballus ascospores had been quantified by means of a physical extraction method in cucurbit fields in south Texas (16), Arizona and California (1,20, 22,24,26,29), Korea Republic (11), and Spain (2). In these studies, $M$. cannonballus ascospores were quantified in soil before planting or at harvest; however, attempts to relate these counts with disease severity were unsuccessful (16). Although Monosporascus root rot and vine decline is considered a typical monocyclic disease (13), there still are no detailed epidemiological studies on ascospore dynamics in soil and disease progression on different cucurbit species.

Preplant soil fumigation with methyl bromide, metham-sodium, chloropicrin, 13-dichloropropene, and methyl iodide, and combining solarization with various fumigants at reduced dosage, have resulted in generally effective control of $M$. cannonballus and increased yield (7,21). However, these practices have both a high economic cost and big environmental impact. Growing muskmelon and watermelon grafted onto Cucurbita rootstocks is becoming one of the most promising control strategies against the vine decline caused by $M$. cannonballus $(5,7)$. In Israel, grafting muskmelon onto Cucurbita rootstocks alone or in combination with methyl bromide provided adequate and reliable disease control $(6-9,18)$. In Spain, watermelon plants grafted onto Cucurbita rootstocks have replaced muskmelon and watermelon crops in the main open-field cucurbit production areas where $M$. cannonballus is present. This change has been progressively adopted by cucurbit growers due to satisfactory results on disease suppression and yield. The good performance of grafting is even allowing for reduced intervals between successive watermelon crops.

The root system of Cucurbita rootstocks seems to be less affected by the disease than muskmelon and watermelon roots. However, it is not known if this is due to resistance to infection, tolerance by its large root system and greater capacity to regenerate roots, or the limitation of conversion of infection to propagules. The effect of Cucurbita rootstocks on the dynamics of soil populations of $M$. cannonballus has not been investigated either. The abandonment of crop rotation might result in an inadvertent increase of $M$. cannonballus population in soil, which may lead to a loss of disease control with grafting. The effect of Cucurbita rootstocks on disease progression and on the dynamic of $M$. cannonballus population in soil needs to be studied in order to assess the fitness of grafting as a control measure.

The main objectives of this work were to (i) determine and compare the soil population dynamics of $M$. cannonballus ascospores in fields grown with three different cucurbit crops: muskmelon, watermelon, and watermelon grafted onto $\mathrm{Cu}$ curbita rootstock during a whole growing season; and (ii) study their relationship with disease progression in these crops.

\section{MATERIALS AND METHODS}

Experimental fields. Two field experiments were conducted in the spring-tosummer cropping season: one in April to July 2003 and the second in May to August 
2004. In both experiments, cucurbit materials used were muskmelon cv. Sancho seedlings, watermelon cv. Dulce Maravilla seedlings, and watermelon cv. Dulce Maravilla seedlings grafted onto Cucurbita maxima $\times C$. moschata rootstock cv. Shintoza.

In 2003, the experimental field (field 1) was located in Almenara (Castellón Province). The plants were transplanted on 25 April onto raised beds spaced $1.5 \mathrm{~m}$ from center to center, with an in-row spacing of $0.75 \mathrm{~cm}$. Each experimental plot was 22.5 $\mathrm{m}$ long and included four rows of 30 plants each. In 2004, the experimental field (field 2) was located in Alboraia (Valencia Province). The plants were transplanted on 25 May onto raised beds, also spaced $1.5 \mathrm{~m}$ from center to center, with an in-row spacing of $0.70 \mathrm{~cm}$. Each experimental plot was $10.5 \mathrm{~m}$ long and included four rows of 15 plants each. In both fields, the experimental design consisted of randomized blocks with four replicates for each of the tested cucurbit crops. Field 1 was drip irrigated and field 2 had furrow irrigation. Standard cultural practices were employed in both fields during the cucurbit growing season.

In both experiments, soil temperature at a 10-cm depth was measured by a soil temperature sensor connected to a data logger (WatchDog data logger, model 450; Spectrum Technologies, Inc, Plainfield, IL).

Soil sampling and ascospore quantification. In both fields, soil samples were taken in eight different moments during the cucurbit growing season from transplanting to harvest time. One additional soil sampling was conducted in September to October, 2 to 3 months after crop termination, before planting noncucurbit winter crops (Table 1). In each experimental plot and sampling moment, six soil samples were taken adjacent to the third row of plants in the upraised beds (in-bed) and six samples from depressed areas between beds of the third and fourth rows of plants (between-bed). Samples of approximately $100 \mathrm{~g}$ were taken randomly with a soil probe at a depth of 10 to $20 \mathrm{~cm}$, which contains the highest population of ascospores (16). This sampling pattern also was adopted for the last sampling moment in September and October.

Soil samples were air dried at room temperature and sifted through a 2-mm sieve to remove soil clods prior to processing. Ascospores of M. cannonballus were extracted by a method adapted from Stanghellini and Rasmussen (25). Each sample was passed through a 250- $\mu \mathrm{m}$ sieve. A 20 -g subsample was mixed with $200 \mathrm{ml}$ of water, agitated on a magnetic stirrer for $5 \mathrm{~min}$, and washed through nested $75-$ and $30-\mu \mathrm{m}$ sieves. The material retained on the $30-\mu \mathrm{m}$ sieve was centrifuged at 2,000 $\times g$ for $4 \mathrm{~min}$. The supernatant was discarded and the pellet was resuspended in 30 to $40 \mathrm{ml}$ of $50 \%$ sucrose and centrifuged for $2 \mathrm{~min}$ at $2,000 \times g$. Ascospores and other materials floating or suspended in the sucrose were decanted onto the $30-\mu \mathrm{m}$ sieve and washed into a clean centrifuge tube. A second sucrose extraction was performed on the residual soil pellet to salvage spores not recovered during the first extraction. The resulting suspension from the second extraction was added to the first, and the combined suspension was stored in a small quantity of water at $4^{\circ} \mathrm{C}$ until analyzed. Characteristic ascospores were enumerated in the water under a stereomicroscope at a magnification of $\times 60$.

Disease assessment and isolation of $M$. cannonballus. In each experimental plot, plants located in the second row were used for disease development. Vine decline symptoms were evaluated visually in each experiment from the second sampling moment until harvest (Table 1). The number of symptomatic plants and the total number of plants evaluated in each plot were used to calculate the incidence of vine decline (percent).

After each disease assessment, two plants were collected arbitrarily from the third row of plants in each experimental plot. Roots of each plant were exposed by carefully washing the soil away. Roots first were inspected visually for evidence of root necrosis. The observation of roots bearing perithecia containing single-spored asci was considered proof of colonization by $M$. cannonballus. In addition, for isolation, small root fragments were surface sterilized for $1 \mathrm{~min}$ in a sodium hypochlorite solution ( $1.5 \%$ active chlorine) and washed twice with sterile water. In all, 21 root fragments per plant from discolored areas of tissue were transferred onto potato dextrose agar (PDA) containing streptomycin sulfate (PDAS) at $0.5 \mathrm{mg} \mathrm{ml}^{-1}$. Plates were examined daily for fungal growth for 7 days, and hyphal tips from all colonies were transferred to PDA for subsequent growth and sporulation.

Data analyses. Data were analyzed using the software Statgraphics Plus 5.1 (Manugistics Inc., Rockville, MD). The counts of the soil samples from each crop and sampling moment were used to compare in-bed and between-bed ascospore populations using one-way analysis of variance (ANOVA). This analysis also was conducted on these data to compare ascospore levels before planting with those obtained 2 to 3 months after crop termination. Means were compared by the least significant difference test $(P \leq 0.05)$. Regression analysis was used to determine the relationship between the percentage of isolation of $M$. cannonballus from roots and days after transplanting. Regression analyses were performed to find the best fit between disease incidence data and days after transplanting according to disease progress models (4).

\section{RESULTS}

Population dynamics of $M$. cannonballus ascospores. The population dynamics of M. cannonballus ascospores in soil for the three cucurbit crops in both experiments are illustrated in Figure 1. This figure represents the mean ascospore densities during the cropping season (sampling moments 1 to 8 ) for both in-bed and between-bed zones.

In field 1 (2003), average initial ascospore density levels were similar for the three cucurbit crops, between 2.12 ascospores $\mathrm{g}^{-1}$ of soil for grafted watermelon quantification and 2.25 ascospores $\mathrm{g}^{-1}$ of soil for watermelon (Fig. 1; Table 2). Ascospore densities in muskmelon and watermelon crops exhibited a similar pattern during the entire cropping season. There was a progressive decrease of the ascospore densities, without significant differences between in-bed and between-bed sampling zones. The minimum values were reached in the fifth sampling moment (57 days after transplanting). From here, there was a quick increase of ascospore densities in both cucurbit crops. At the end of the cropping season, significant differences were observed between in-bed and between-bed ascospore counts, reaching 4.91 and 2.94 ascospores $\mathrm{g}^{-1}$ of soil for inbed and between-bed sampling zones, respectively, in the muskmelon treatment, and 4.67 and 2.56 ascospores $\mathrm{g}^{-1}$ of soil for in-bed and between-bed sampling zones, respectively, in the watermelon treatment. In contrast, the population dynamics of $M$. cannonballus ascospores in the grafted watermelon treatment was very different, remaining stable throughout the entire cropping season.

In field 2 (2004), the population dynamics observed for the three cucurbit crops were similar to those illustrated for field 1 . In this case, average initial ascospore density levels were slightly higher, between 3.05 ascospores $\mathrm{g}^{-1}$ of soil for watermelon and 3.13 ascospores $\mathrm{g}^{-1}$ of soil for muskmelon (Fig. 1; Table 2). Ascospore densities in the muskmelon and watermelon treatments exhibited a progressive decrease

Table 1. Sampling moments conducted in the experimental field 1, located in Almenara, Castellón Province (2003) and field 2, located in Alboraia, Valencia Province (2004)

\begin{tabular}{lcc}
\hline & \multicolumn{2}{c}{ Days after transplanting } \\
\cline { 2 - 3 } Moment no. & $\mathbf{2 0 0 3}$ & $\mathbf{2 0 0 4}$ \\
\hline 1 & 0 & 0 \\
2 & 19 & 16 \\
3 & 29 & 27 \\
4 & 39 & 37 \\
5 & 57 & 48 \\
6 & 71 & 56 \\
7 & 85 & 65 \\
8 & 98 & 76 \\
9 & 142 & 133 \\
\hline
\end{tabular}

${ }^{\mathrm{z}}$ Plants were transplanted on 25 April 2003 and 25 May 2004. 
without significant differences between inbed and between-bed sampling zones. The lowest values were reached in the fourth sampling moment (37 days after transplanting) and in the sixth sampling moment (56 days after transplanting) for muskmelon and watermelon crops, respectively. Subsequently, there was a rapid increase of ascospore densities. At the end of the cropping season, significant differences were observed between in-bed and between-bed ascospore counts, reaching 5.99 and 4.55 ascospores $\mathrm{g}^{-1}$ of soil for in-bed and between-bed sampling zones, respectively, in the muskmelon treatment, and 6.26 and 4.50 ascospores $\mathrm{g}^{-1}$ of soil for in-bed and between-bed sampling zones, respectively, in the watermelon treatment. Counts of $M$. cannonballus ascospores in the grafted watermelon treatment also remained stable in field 2 during the entire cropping season.
In both experimental fields, the result of the $M$. cannonballus ascospore counts performed 2 to 3 months after crop termination are shown in Table 2. In general, there was a significant increase on ascospore populations in soils cropped to muskmelon and watermelon compared with ascospore levels of grafted watermelon that showed a slight decrease. In field 1, this increase was of 55.05 and $62.66 \%$ for muskmelon and watermelon crops, respectively, while, in field 2, the increase was of 5.11 and $10.82 \%$ for muskmelon and watermelon, respectively, although only the latter was statistically different.

Isolation of $\boldsymbol{M}$. cannonballus. The isolation percentages of $M$. cannonballus from roots of the three cucurbit crops during the cropping season in both fields are illustrated in Figure 2. In field 1 (2003), $M$. cannonballus first was isolated from the roots of the three cucurbit crops in the fourth sampling moment (39 days after transplanting); however, during the cropping season, these percentages were always higher on muskmelon and watermelon roots compared with the roots of the rootstock of grafted watermelon. The incidence of $M$. cannonballus on muskmelon and watermelon reached 45.3 and $29.8 \%$ of isolation, respectively, by the sixth sampling moment (71 days after transplanting) when roots were severely damaged. In these crops, there was a significant linear relationship between isolation percentages and days after transplanting whereas, in grafted watermelon, this relationship was not significant (Fig. 2). Perithecia of $M$. cannonballus were observed on muskmelon and watermelon roots from the sixth sampling moment, but never on Cucurbita rootstock roots.
Field 1 (2003)
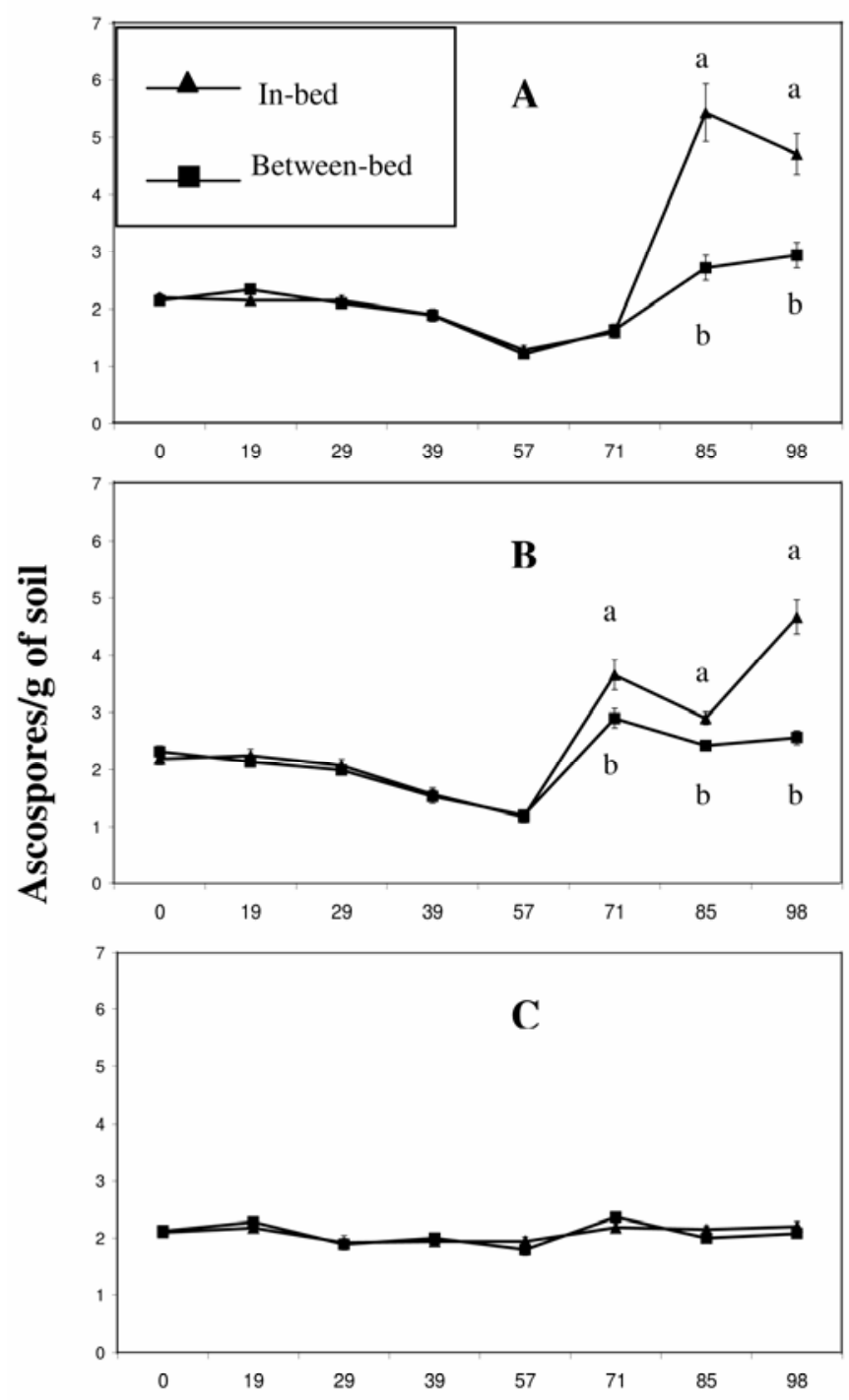

Days after transplanting
Field 2 (2004)
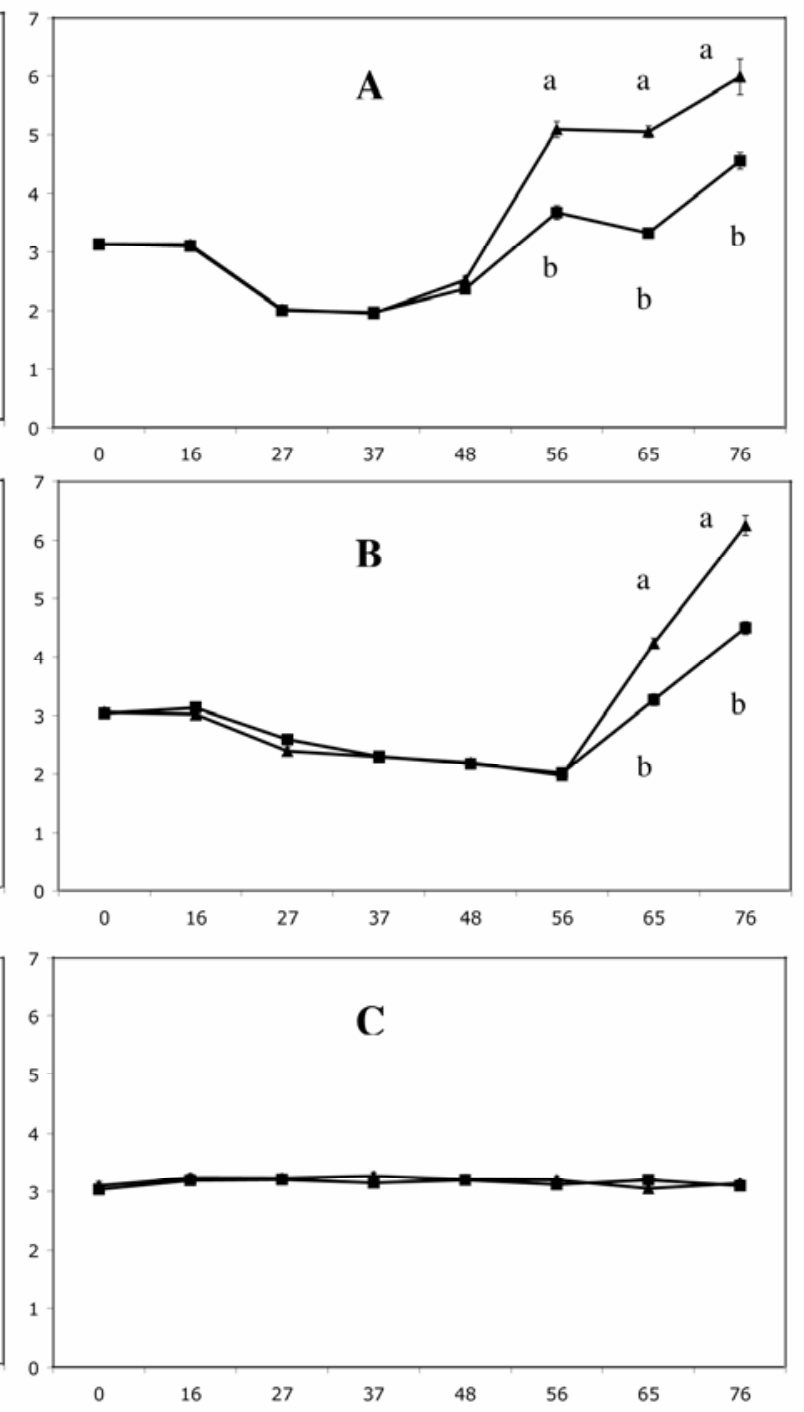

Days after transplanting

Fig. 1. Population dynamics of ascospores of Monosporascus cannonballus in three different cucurbit crops (A, muskmelon; B, watermelon; and C, grafted watermelon) at various times after transplanting in field 1 (2003) and field 2 (2004). Data are the mean of four replications each year. The vertical bars are the standard errors of the mean. Different letters above the bars indicate statistical difference according to the least significant difference test $(P \leq 0.05)$. 
In field 2 (2004), M. cannonballus first was isolated from the roots of the three cucurbit crops in the third sampling moment (27 days after transplanting). The isolation percentages of the pathogen also were higher from muskmelon and watermelon roots, reaching 67.3 and $81.0 \%$ respectively, by the sixth sampling mo- ment (56 days after transplanting), whereas the maximum isolation percentage on the roots of the rootstock of grafted watermelon was $21.4 \%$, also by the sixth sampling moment. In all crops, there was a significant linear relationship between the isolation percentage and days after transplanting (Fig. 2). Perithecia of M. cannon-

Table 2. Monosporascus cannonballus ascospore counts immediately after transplanting (sampling moment 1 ) and 2 to 3 months after crop termination (sampling moment 9) in field 1 (2003) and field 2 $(2004)^{\mathrm{Z}}$

\begin{tabular}{lccc}
\hline Crop & Sampling moment 1 & Sampling moment 9 & Increase (\%) \\
\hline Field 1 & & & \\
Muskmelon & $2.18 \pm 0.05 \mathrm{a}$ & $3.38 \pm 0.13 \mathrm{~b}$ & 55.05 \\
Watermelon & $2.25 \pm 0.07 \mathrm{a}$ & $3.66 \pm 0.09 \mathrm{~b}$ & 62.66 \\
Grafted watermelon & $2.12 \pm 0.05 \mathrm{a}$ & $2.04 \pm 0.06 \mathrm{a}$ & -3.77 \\
Field 2 & $3.13 \pm 0.04 \mathrm{a}$ & $3.29 \pm 0.06 \mathrm{a}$ & 5.11 \\
Muskmelon & $3.05 \pm 0.05 \mathrm{a}$ & $3.38 \pm 0.07 \mathrm{~b}$ & 10.82 \\
Watermelon & $3.07 \pm 0.05 \mathrm{a}$ & $2.95 \pm 0.05 \mathrm{a}$ & -3.91 \\
Grafted watermelon & & & \\
\hline
\end{tabular}

${ }^{\mathrm{z}}$ Values of ascospore populations are the mean of 48 soil samples ( 6 in-bed and 6 between-bed soil samples in each of the experimental plots) \pm standard error of the mean. Numbers followed by the same letter are not statistically different according to the least significant difference test $(P \leq 0.05)$.

ballus were observed only on muskmelon roots and watermelon roots from the fifth and the seventh sampling moments, respectively.

Mean soil temperatures at $10 \mathrm{~cm}$ in field 1 ranged between 23.7 and $28.0^{\circ} \mathrm{C}$, increasing progressively over $25^{\circ} \mathrm{C}$ from 8 June (49 days after transplanting). In field 2 , mean soil temperatures ranged from 20.6 to $26.8^{\circ} \mathrm{C}$, increasing progressively over $25^{\circ} \mathrm{C}$ from 11 June (17 days after transplanting).

Disease progression. In both experiments, symptoms of vine decline were observed only on muskmelon and watermelon crops, while grafted watermelon remained asymptomatic. Results of disease progression on muskmelon and watermelon crops are shown in Figure 2.

In field 1 (2003), vine decline symptoms were observed beginning at the fifth sampling moment (57 days after transplanting) for both muskmelon and watermelon crops. The incidence of $100 \%$ symptomatic plants was reached in the eighth

\section{Field 1 (2003)}

\section{Field 2 (2004)}
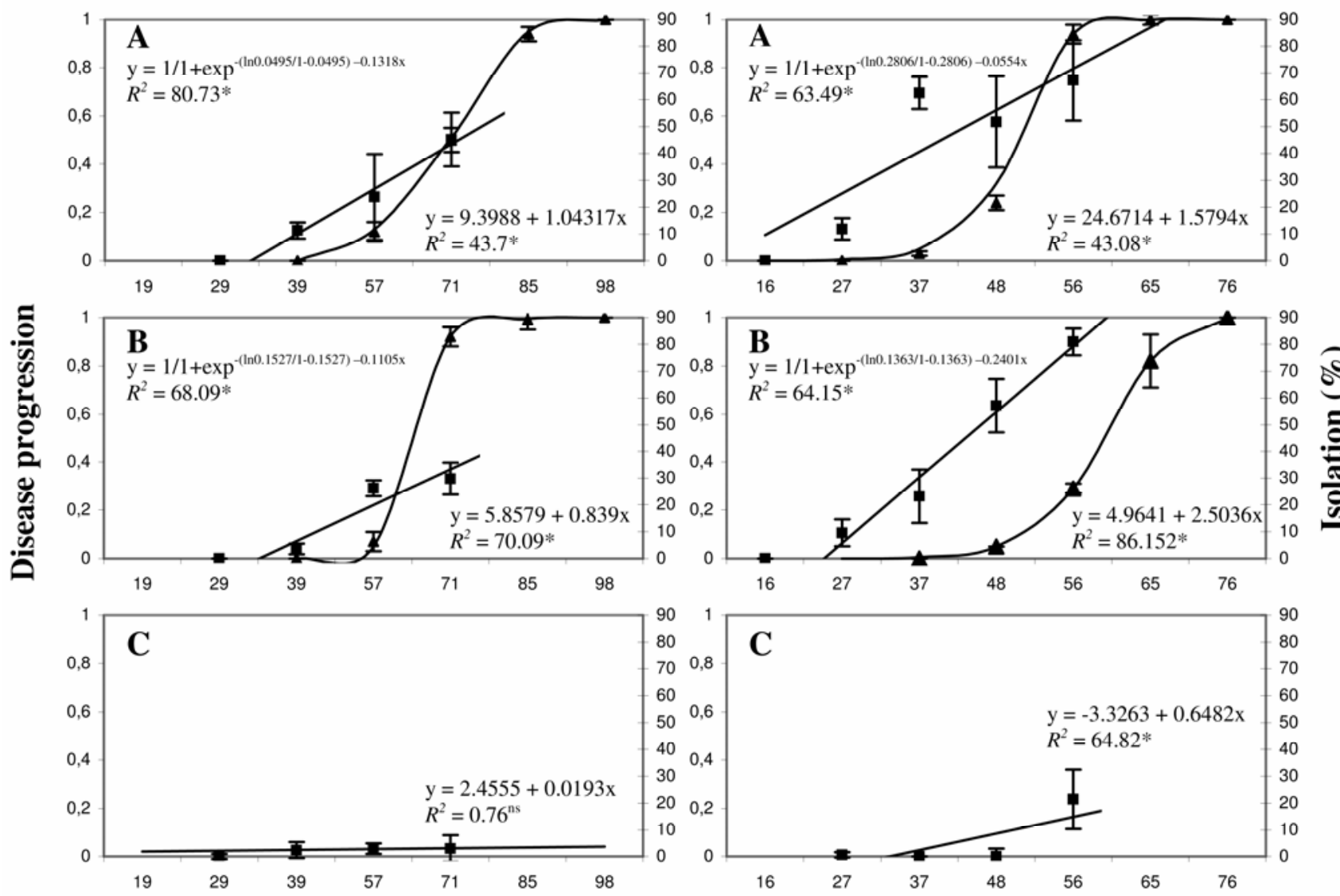

\section{Days after transplanting}

\section{Days after transplanting}

Fig. 2. Disease progression curves $(\mathbf{\Delta})$ of A, muskmelon and $\mathbf{B}$, watermelon crops in field 1 (2003) and field 2 (2004), expressed as percentage of symptomatic plants at various days after transplanting $(\mathrm{ns}=$ not significant and $*=P \leq 0.05)$. Data are the mean of four replications each year. The vertical bars are the standard errors of the mean. Regression analysis between the isolation percentage of Monosporascus cannonballus from roots ( $\mathbf{\square})$ of three cucurbit crops (A, muskmelon; B, watermelon; and C, grafted watermelon) and days after transplanting in field 1 (2003) and field $2(2004)(\mathrm{ns}=$ not significant and $*=P \leq$ 0.05). Data are the mean of four replications each year. The vertical bars are the standard errors of the mean. 
sampling moment (98 days after transplanting) and seventh sampling moment (85 days after transplanting) for muskmelon and watermelon, respectively. Disease progress data were best correlated with a logistic model. In field 2 (2004), vine decline symptoms on muskmelon were observed beginning at the fourth sampling moment (37 days after transplanting) but first symptoms on watermelon plants were observed later, from the fifth sampling moment (48 days after transplanting). In both cases, the incidence of $100 \%$ symptomatic plants was reached at the eight sampling moment (76 days after transplanting). Exponential and logistic models showed the best correlation with disease progression data of muskmelon and watermelon crops, respectively.

\section{DISCUSSION}

One of the major objectives of this study was to determine the population dynamics of $M$. cannonballus ascospores in fields grown with three different cucurbit crops during an entire growing season. On muskmelon and watermelon, in both years of study, there was a slight and progressive decrease in the number of ascospores per gram of soil from transplanting until first symptoms of vine decline were observed. This could be explained by the germination of ascospores in the plant rhizosphere and the subsequent root infection, which occurs when stimulated by root exudates and soil microflora $(22,23)$. This decrease was observed in both in-bed and betweenbed soil samples without statistical differences, indicating the extension of root development and exudates throughout the root zone in the experimental fields.

The lowest density of $M$. cannonballus ascospores in muskmelon and watermelon crops coincided approximately with the observation of the first symptoms of vine decline: 57 days after transplanting for both crops in field 1 and 37 and 56 days after transplanting for muskmelon and watermelon, respectively in field 2 . From that moment, there was a remarkable increase of ascospore counts parallel to the rapid development of vine decline symptoms, which led to the death of the plants. This increase probably was the consequence of the production of M. cannonballus ascospores from perithecia developed on roots and their incorporation into soil. First perithecia were observed 71 days after transplanting on muskmelon and watermelon roots in field 1 and 48 and 65 days after transplanting on muskmelon and watermelon roots, respectively, in field 2 . Several authors pointed out that ascospore production occurs primarily at the end of the cropping season, especially after crop termination $(26,29)$. Nevertheless, in our experimental fields, perithecia were observed some weeks before the complete death of the plants. Our observations are in agreement with those of Pivonia et al. (19) who, in Israel, found mature perithecia on dead secondary and tertiary muskmelon roots before fruit maturation. It seems that soil temperature governs, in part, the rate of reproduction of the pathogen. Waugh et al. (29) demonstrated that optimal temperatures for perithecia development must be between 25 and $30^{\circ} \mathrm{C}$ and Pivonia et al. (19) suggested $25^{\circ} \mathrm{C}$ as the lower threshold or critical temperature for disease development. In our study, mean soil temperatures reached this threshold soon after crop transplanting.

The increase of ascospore counts in the late stages of muskmelon and watermelon crops showed significant differences between in-bed and between-bed soil samples. These differences could be related to a higher root density in the in-bed root area which resulted in a higher production of perithecia and ascospores (16).

First isolations of $M$. cannonballus from muskmelon, watermelon, and Cucurbita rootstock roots were obtained 39 and 27 days after transplanting in field 1 and field 2 , respectively. The percentage of isolation increased linearly during the cropping season from roots of muskmelon and watermelon crops, being highest when roots were highly deteriorated, perithecia were found, and disease incidence increased rapidly. In contrast, the isolation frequency of $M$. cannonballus from Cucurbita roots was considerably lower than from muskmelon and watermelon. Similar results were obtained by Mertely et al. (15), who inoculated $M$. cannonballus to nine cucurbit species under greenhouse conditions and artificially infested microplots. All cucurbits were susceptible to $M$. cannonballus, although the pathogen was isolated readily from diseased roots of muskmelon and watermelon, whereas it was recovered with more difficulty from Cucurbita spp. (C. maxima Duchesne, $C$. moschata (Duchesne) Duchesne ex Poir., and $C$. texana A. Gray). Watermelon were severely affected, with severe top weight reductions, whereas Cucurbita spp., in general, were less stunted. These authors indicated that perithecia were observed on the roots of Cucurbita spp. in microplot experiments but in only one of the two greenhouse tests performed. In our study, perithecia were never observed on the rootstock roots.

Apparently, the roots of the C. maxima $\times C$. moschata cv. Shintoza rootstock did not stimulate the germination of $M$. cannonballus ascospores, and root infection was very low. C. maxima, C. maxima $\times C$. moschata, and $C$. moschata $\times C$. moschata rootstocks have been widely used in grafting research against Monosporascus root rot vine decline in Israel, showing their efficacy to control this disease (5-9).

Two to three months after harvest, soil ascospore densities increased more than $50 \%$ in muskmelon and watermelon crops when compared with the initial population in field 1. In the second study, only watermelon significantly $(P \leq 0.05)$ increased $(10.8 \%)$ ascospore densities. This is in agreement with the high reproductive potential of M. cannonballus on the roots of susceptible hosts (29). Unfortunately, in the present study, it was not possible to quantify these levels later in the year due to the new crops planted in these fields in winter and the respective cultural practices applied.

The differential ascospore dynamics and pattern of isolation of the pathogen from roots observed among grafted and nongrafted cucurbit crops was in agreement with the differences observed in disease progression. In all experiments, vine decline symptoms were observed on muskmelon and watermelon crops but not on grafted watermelon.

In Arizona and California, Monosporascus root rot vine decline incidence, measured as percentage of plants infected during spring and autumn cropping seasons, was fitted to a monomolecular disease progress model (24). Although, in our study, root colonization adjusted to firstorder linear equations, disease progression on muskmelon and watermelon best correlated with exponential and logistic models. According to the proposals of Van Der Plank (28), the monomolecular and linear models better describe monocyclic diseases and the logistic models are most appropriate for polycyclic diseases. Thus, our results might lead to doubt about the monocyclic behavior of Monosporascus root rot and vine decline. Pfender (17) indicated that, in monocyclic soilborne pathogens, when the amount of disease is measured as the number of plants showing advanced symptoms, disease progress curves are more subject to environment and hosts factors than infection alone, being poorly described by the monomolecular equation. In plants affected by Monosporascus root rot and vine decline, canopy wilting happens when root infection reaches a maximum and evapotranspiration is high due to hot weather. In Spain, these factors coincide only during the weeks prior to fruit maturity. Consequently, vine decline severity increases exponentially in just 1 or 2 weeks. Our results showed that a disease can be fitted to different models depending on the severity parameter analyzed. Therefore, as has been stated previously by other authors, the biological nature of a pathosystem cannot be ascertained just because one model is more appropriate than another $(4,17)$.

The influence of susceptible muskmelon and watermelon crops on the ascospore population dynamics is in concordance with the disease cycle of $M$. cannonballus in terms of ascospore germination, root infection, symptom development, and formation of perithecia, which produce new ascospores. In contrast, there was no 
vine decline in grafted watermelon, and only a small percentage of the Cucurbita rootstock roots were infected by $M$. cannonballus. Furthermore, perithecia were never observed on the rootstock roots. In fact, ascospore soil populations on grafted watermelon remained stable during the whole cropping season or showed a slight decrease 2 to 3 months after crop termination. Consequently, disease control by grafting onto Cucurbita spp. seems to be related primarily by the increased resistance of its root system to infection by $M$. cannonballus because of lack of recognition between the host and the pathogen. Cohen et al. (7) warned about the potential loss of disease control with grafting due to build up of $M$. cannonballus inoculum in the soil by continuous usage of Cucurbita rootstocks. However, this study demonstrated that the reproductive potential of $M$. cannonballus on Cucurbita rootstock was very low, providing further evidence of the use of grafting as a disease management measure for this disease.

\section{ACKNOWLEDGMENTS}

This research was financially supported by the Spanish Comisión Interministerial de Ciencia y Tecnología (AGF97-1208-C03-01) and Ministerio de Ciencia y Tecnología (AGL2000-1809-C03-01). We thank C. Baixauli (Fundación Ruralcaja, Valencia) and A. Miguel (IVIA, Valencia) for the facilities given to conduct field experiments; and E. García-Parejo, P. Peris, M. Lozano, R. Esteve, and J. M. Rodríguez-Reina for their technical assistance.

\section{LITERATURE CITED}

1. Aegerter, B. J., Gordon, T. R., and Davis, R. M. 2000. Occurrence and pathogenicity of fungi associated with melon root rot and vine decline in California. Plant Dis. 84:224-230.

2. Beltrán, R., Vicent, A., García-Jiménez, J., and Armengol, J. 2007. Quantification of Monosporascus cannonballus ascospores in muskmelon fields in eastern Spain. J. Phytopathol. 155:248-250.

3. Beltrán, R., Vicent, A., Sales, R., Jr., GarcíaJiménez, J., and Armengol, J. 2005. Population dynamics of Monosporascus cannonballus ascospores in marsh soils in eastern Spain. Eur. J. Plant Pathol. 113:357-365.

4. Campbell, C. L., and Madden, L. V. 1990. Introduction to plant disease epidemiology. Wiley-Interscience Publication, New York.
5. Cohen, R., Burger, J., Horev, C., Koren, A., and Edelstein, M. 2007. Introducing grafted cucurbits to modern agriculture. The Israeli experience. Plant Dis. 91:916-923.

6. Cohen, R., Burger, Y., Horev, C., Porat, A., and Edelstein, M. 2005. Performance of Galia-type melons grafted on to Cucurbita rootstock in Monosporascus cannonballus-infested and non-infested soils. Ann. Appl. Biol. 146:381387.

7. Cohen, R., Pivonia, S., Burger, J., Edelstein, M., Gamliel, A., and Katan, J. 2000. Toward integrated management of Monosporascus wilt of melons in Israel. Plant Dis. 84:496-505.

8. Edelstein, M., Burger, Y., Horev, C., Porat, A., Meir, A., and Cohen, R. 2004. Assessing the effect of genetic and anatomic variation of $\mathrm{Cu}$ curbita rootstocks on vigour, survival and yield of grafted melons. J. Hortic. Sci. Biotechnol. 79:370-374.

9. Edelstein, M., Cohen, R., Burger, Y., Shriber, S., Pivonia, S., and Shtienberg, D. 1999. Integrated management of sudden wilt in melons, caused by Monosporascus cannonballus, using grafting and reduced rates of methyl bromide. Plant Dis. 83:1142-1145.

10. García-Jiménez, J., Armengol, J., Sales, R., Jordá, C., and Bruton, B. D. 2000. Fungal pathogens associated with melon collapse in Spain. EPPO Bull. 30:169-173.

11. Heo, N. Y., Ryu, K. Y, and Lee, Y. B. 2001. Cultural characteristics and ascospore density in soil of Monosporascus cannonballus on $\mathrm{Cu}-$ curbitaceae plants. Res. Plant Dis. 7:16-19.

12. Infantino, A., Ciuffreda, G., Montuschi, C., Carlucci, A., Pucci, N., Savino, A., and Frisullo, S. 2002. Fungi associated with vine decline and root rots of cucurbits in Italy. J. Plant Pathol. 84:183.

13. Martyn, R. D., and Miller, M. E. 1996. Monosporascus root rot and vine decline: an emerging disease of melons worldwide. Plant Dis. 80:716-725.

14. Mertely, J. C., Martyn, R. D., Miller, M. E., and Bruton, B. D. 1991. Role of Monosporascus cannonballus and other fungi in a root rot/vine decline disease of muskmelon. Plant Dis. 75:1133-1137.

15. Mertely, J. C., Martyn, R. D., Miller, M. E., and Bruton, B. D. 1993. An expanded host range for the muskmelon pathogen Monosporascus cannonballus. Plant Dis. 77:667-673.

16. Mertely, J. C., Martyn, R. D., Miller, M. E., and Bruton, B. D. 1993. Quantification of Monosporascus cannonballus ascospores in three commercial muskmelon fields in South Texas. Plant Dis. 77:766-771.

17. Pfender, W. F. 1982. Monocyclic and polycyclic root diseases: distinguishing between the nature of the disease cycle and the shape of the disease progress curve. Phytopathology 72:31-32.
18. Pivonia, S., Cohen, R., Katan, J., Burger, Y., Ben Ze'ev, I. S., Karchi, Z., and Edelstein, M. 1996. Sudden wilt of melons in southern Israel. Pages 285-290 in: Proc. 6th Eucarpia Meet. Cucurbit Genet. Breed.

19. Pivonia, S., Cohen, R., Kigel, J., and Katan, J. 2002. Effect of soil temperature on disease development in melon plants infected by Monosporascus cannonballus. Plant Pathol. 51:472479.

20. Radewald, K. C., Ferrin, D. M., and Stanghellini, M. E. 2004. Sanitation practices that inhibit reproduction of Monosporascus cannonballus in melon roots left in the field after crop termination. Plant Pathol. 53:660-668.

21. Stanghellini, M. E., Ferrin, D. M., Kim, D. H., Waugh, M. M., Radewald, K. C., Sims, J. J., Ohr, H. D., Mayberry, K. S., Turini, T., and McCaslin, M. A. 2003. Application of preplant fumigants via drip irrigation systems for the management of root rot of melons caused by Monosporascus cannonballus. Plant Dis. 87:1176-1178.

22. Stanghellini, M. E., Kim, D. H., and Rasmussen, S. L. 1996. Ascospores of Monosporascus cannonballus: germination and distribution in cultivated and desert soils in Arizona. Phytopathology 86:509-514.

23. Stanghellini, M. E., Kim, D. H., and Waugh, M. 2000. Microbe-mediated germination of ascospores of Monosporascus cannonballus. Phytopathology 90:243-247.

24. Stanghellini, M. E., Kim, D. H., Waugh, M. M., Ferrin, D. M., Alcantara, T., and Rasmussen, S. L. 2004. Infection and colonization of melon roots by Monosporascus cannonballus in two cropping seasons in Arizona and California. Plant Pathol. 53:54-57.

25. Stanghellini, M. E., and Rasmussen, S.L. 1992. A quantitative method for the recovery of ascospores of Monosporascus cannonballus from field soil. (Abstr.) Phytopathology 82:1115.

26. Stanghellini, M. E., Waugh, M. M., Radewald, K. C., Kim, D. H., Ferrin, D. M., and Turini, T. 2004. Crop residue destruction strategies that enhance rather than inhibit reproduction of Monosporascus cannonballus. Plant Pathol. 53:50-53.

27. Uematsu, S., Hirota, K., Shiraishi, T., Ooizumi, T., Sekiyama, K., Ishikura, H., and Edagawa Y. 1992. Monosporascus root rot of bottle gourd stock of watermelon caused by Monosporascus cannonballus. Ann. Phytopathol. Soc. Jpn. 20:312-316.

28. Van Der Plank, J. E. 1963. Plant Diseases: Epidemics and Control. Academic Press, Inc. New York.

29. Waugh, M. M., Kim, D. H., Ferrin, D. M., and Stanghellini, M. E. 2003. Reproductive potential of Monosporascus cannonballus. Plant Dis. 87:45-50. 